\title{
Spatiotemporal measurements with an ultrafast scanning tunneling microscope
}

\author{
Jensen, Jacob Riis; Keil, Ulrich Dieter Felix; Hvam, Jørn Märcher
}

Published in:

Summaries of Papers Presented at the Conference on Lasers and Electro-Optics

Publication date:

1997

Document Version

Publisher's PDF, also known as Version of record

Link back to DTU Orbit

Citation (APA):

Jensen, J. R., Keil, U. D. F., \& Hvam, J. M. (1997). Spatiotemporal measurements with an ultrafast scanning tunneling microscope. In Summaries of Papers Presented at the Conference on Lasers and Electro-Optics (Vol. Volume 11, pp. 298-298). IEEE.

\section{General rights}

Copyright and moral rights for the publications made accessible in the public portal are retained by the authors and/or other copyright owners and it is a condition of accessing publications that users recognise and abide by the legal requirements associated with these rights.

- Users may download and print one copy of any publication from the public portal for the purpose of private study or research.

- You may not further distribute the material or use it for any profit-making activity or commercial gain

- You may freely distribute the URL identifying the publication in the public portal 
3. N. S. Patel, K. L. Hall, K. A. Rauschenbach, Opt. Lett. 21, no. 18, 1466 (1996).

4. K. Uchiyama, S. Kawanishi, H. Takara, T. Morioka, M. Saruwatari, Electron. Lett. 30, no. 11, 873 (1994).

5. E. Portnoi, V. B. Gorfinkel, E. A. Avrutin, I. G. Thayne, D. A. Barrow, J. H. Marsh, S. Luryi, IEEE J. Select. Top. in Quantum Electron. 1, no. 2, 451 (1995).

6. R. Esman, Tech. Digest for OFC '96, p. 214, paper ThC5, San Jose, Calif. (1996).

\section{CW02}

4:45 pm

Spatiotemporal measurements with an ultrafast scanning tunneling microscope

Jacob R. Jensen, Ulrich D. Keil, Jørn M. Hvam, Mikroelektronik Centret, DTU build. 345 east, DK-2800 Lyngby, Denmark

We use an ultrafast scanning tunneling microscope (USTM) to resolve voltage transients propagating on a coplanar waveguide (CPW). The photoconductive (PC) switch connected to the tunneling tip is illuminated through a fiber with a 100-fs Ti:sapphire laser (Fig. 1). The laser pump beam generates a voltage pulse on the CPW; the probe beam gates the current picked up by the tunneling tip. Sample and probe substrates are low temperature grown GaAs. The use of a fiber enables flexible positioning of the tip over a range of $50 \mu \mathrm{m}$ (only limited by the scanning range of the piezo tube). The instrument can be used to map out voltage transients generated by different excitation on the CPW in detail. In the presented measurements the tip is stepped across the CPW; at each position the delay time is varied.

Figure 2 shows a gray-scale contour plot of a pulse generated by illuminating an in-line gap of a CPW. The main signal (at delay time, $\tau=$ $11 \mathrm{ps}$ ) is confined to the center electrode where the voltage is initially increased at the photoconductive switch. With measurements in which the tip is in contact we test the laser position and ensure that the voltage is only

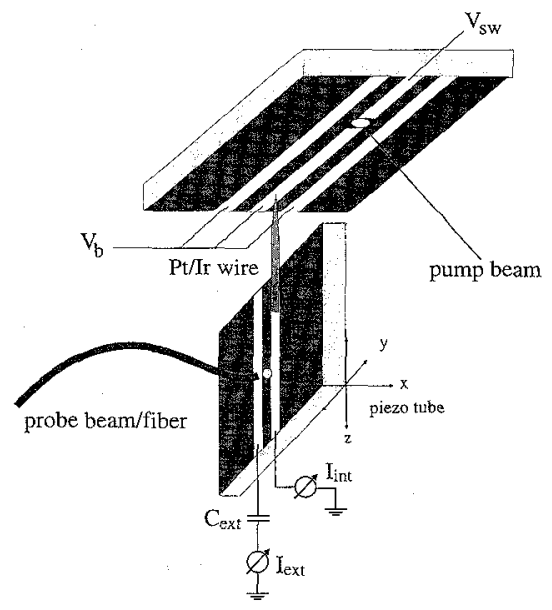

CWO2 Fig. 1 Schematic setup of the USTM. The probe consists of a $5-\mu \mathrm{m} \mathrm{Pt} / \mathrm{Ir}$ wire glued to the $10-\mu \mathrm{m}$ transmission line. The other end of the wire forms the tunneling tip. The sliding contact photoconductive switch is illuminated through a fiber that is glued in place.

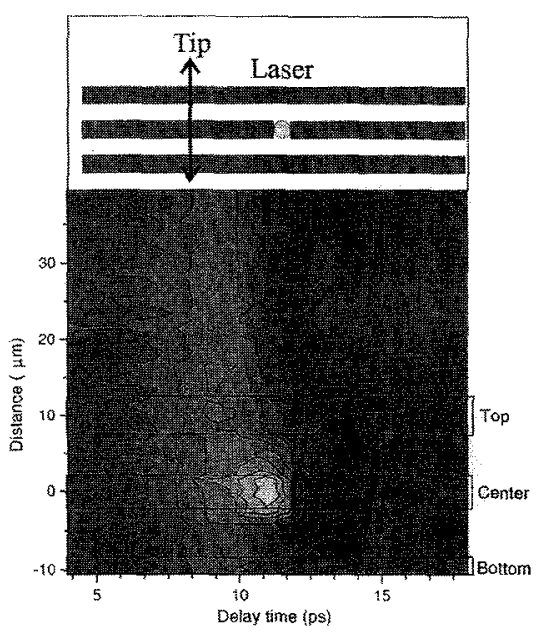

inset, Fig. 3), the transient signal map shows more detail. Only the pulse on the center line is reflected from the in-line gap $(\tau=13 \mathrm{ps})$. This reflection contains a common mode contribution. Measurements on the other side of the gap show that the pulse on the bottom line continues beyond the gap. Here the signal on the center line has been blocked by the gap.

In summary, we demonstrate the use of a USTM for mapping voltage transients on transmission lines and show that the instrument works as a transient voltage probe coupled through the geometrical capacitance of the tip-electrode gap.

\section{CW03 (Invited)}

$5: 00 \mathrm{pm}$

Optical imaging of picosecond switching in CMOS circuits

CWO2 Fig. 2 Spatiotemporal measurement of a voltage transient generated with an in-line gap on a coplanar waveguide displayed by a grayscale contour plot. White represents the maximum amplitude and black the minimum amplitude. The illumination principle is illustrated on top.

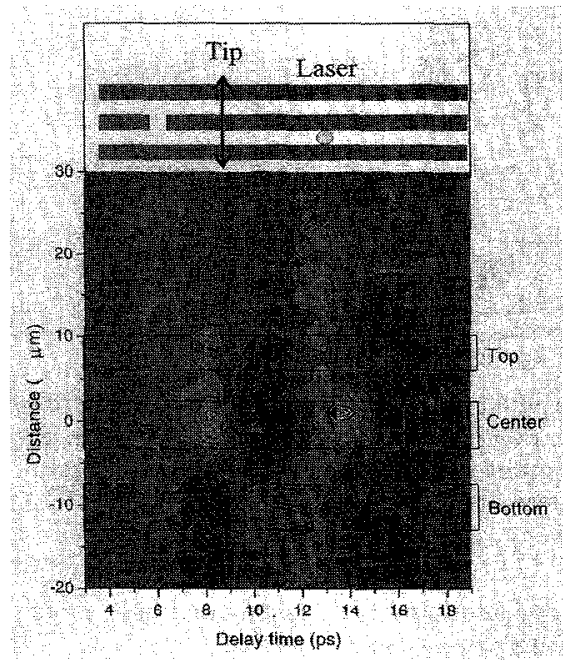

CWO2 Fig. 3 Gray-scale contour plot of a voltage transient generated by excitation between the lines. The illumination principle is illustrated on top.

increased on the center line. Figure 1 shows that there is an additional contribution that is preceding the main pulse and extending over the whole scanning range. We explain this result with the pulse generation principle; by illuminating an in-line gap we generate a differential mode together with a common mode. The field lines for the common mode spread out in space to the closest ground electrode.

We test this explanation by exciting a pulse between the center and bottom lines of the waveguide. In this case, the voltage on the center bias line is decreased and increased on the ground line, and a pure differential mode is generated (Fig. 3). The initial pulse $(\tau=8 \mathrm{ps})$ is confined to the two electrodes and does not show any trailing, unconfined components. Because of a reflection from the in-line gap (see
J. A. Kash, J. C. Tsang, IBM Research Division, Thomas J. Watson Research Center, Yorktown Heights, New York, 10598; E-mail:kash@watson.ibm.com

Measuring the time at which individual de vices switch inside present and future submicron scale CMOS circuits poses substantial challenges. A practical technique must be capable of probing large numbers of devices with time resolution exceeding $100 \mathrm{ps}$. Ideally, the method should work on conventional devices under normal operation conditions, and require no extra test structures on the chip. The technique must be useful as device dimensions shrink and circuit complexity increases. The increasing number of metalization layers and "flipchip" packaging will add the challenge of a front surface inaccessible at the device level. These technological advances will cause the present internal test method that uses electron beam probing to become ineffective, so alternative methods are urgently needed.

We have found that hot electron light emission is generated as a subnanosecond pulse coincident with the normal switching of each individual FET in a CMOS circuit. ${ }^{2}$ Here we use this emission to directly measure the propagation of signals through the individual gates in fully functional CMOS circuits. Our implementation (Fig. 1) uses an imaging microchannelplate photomultiplier as a detector. ${ }^{3}$ Time resolution is obtained by photon timing over a repetitive electrical waveform. Gate-to-gate switching delays of less than $50 \mathrm{ps}$ can be resolved, and the switching of hundreds of FETs can be simultaneously observed. As model circuits, we use CMOS ring oscillators and counters (Fig. 2a) fabricated with an effective gate length of $0.6 \mu \mathrm{m}$. Images of the optical emission are shown in Figs. $2(\mathrm{~b}-\mathrm{d})$. A series of

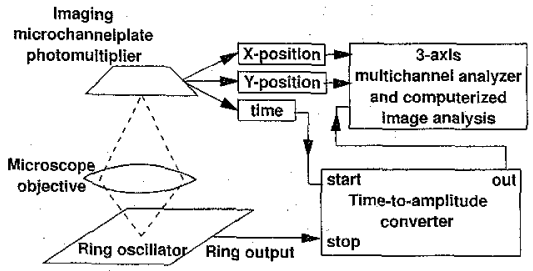

CWO3 Fig. 1 Schematic of the experimental apparatus. 